\title{
Four challenges for the future of digital politics research
}

\author{
Andrew Chadwick
}

\section{Introduction}

In our post-2016 moment - after the inaccurate and misleading Facebook advertising in the Brexit referendum; after the disinformation and misinformation crisis of the 2016 United States presidential campaign; after revelations of the massive scale of automated social media activity designed to manipulate public attention during key political events, some of it sponsored by Russian intelligence agencies; after the Cambridge Analytica/Facebook data breach scandal; after the live-streamed New Zealand terrorist massacre of March 2019 - the mood among digital media researchers is one of deep pessimism. So much has been lost of the optimistic visions for democratic change that once underlay scholarship in the field. Yet, even more troubling is the view that many of the pathologies of the post-2016 crisis have always been present in some form but were too often neglected. There is currently profound uncertainty about the long-term impact of all forms of digital media on civic life, but this is especially the case for social media platforms, which for many people have become the de facto Internet.

In this chapter I argue that there are four epistemological challenges facing digital politics researchers. Addressing these challenges is one way (and I hasten to add that it is only one way among many) to better equip the field for researching the post-2016 context. I also make a broader argument, which boils down to the following: in the social sciences, there are times when it is useful to shift the focus away from institutions and organizations and towards the analysis of impulses, emotions, identities and beliefs; in other words, public opinion. In the analysis of digital media and politics, that time has come. 
Twenty years of research, mostly driven by normatively pro-digital media perspectives which mainly focused on whether online 'engagement' was being sufficiently embedded in political or journalistic institutions, has obscured some important questions about the properties of that engagement and the origins and consequences of digitally shaped attitudes and behaviours more generally. I want to argue that this legacy has made it more difficult for scholars to appreciate some problematic aspects of how digital media are reshaping how public opinion is formed, and how the civic culture of liberal democracies is evolving.

\section{Four challenges for future research}

The legacy of research on digital media and politics over the last two decades presents four interrelated challenges for future work in the field. I hasten to add that I have no easy solutions to these problems. In passing, I should also say that some of my own research has almost certainly contributed to them.

Analyses of digital media and politics have tended to select cases that are progressive or pro-liberal democratic

The growth of digital politics scholarship over the last two decades has mostly been fuelled by analyses of broadly progressive or pro-democratic cases (Schradie, 2019). Probably the best examples of this were the outpourings of optimistic scholarship on the 2008 Obama presidential campaign in the United States (US), and the events of 2010-11 that prematurely became known as the Arab Spring. At the level of individual interventions, probably the most significant landmark was Shirky's (2008) highly influential book Here Comes Everybody. But this selection bias extends in diverse ways across all kinds of cases, from political parties to social movements, to community activism, to news and journalism. Its roots are deep, complex and manifold, but an important explanation is that much scholarship on digital media and politics emerged from an instinctive critique of the elitism of the mass broadcast media system. The explosion of the Internet at the turn of this century proved so exciting because it appeared to be sweeping all of that away. It promised to usher in new forms of politics characterized by flatter hierarchies, the empowerment of the previously powerless, and a new culture of openness, tolerance and global cosmopolitanism. So many of the animating concepts in digital politics research owe their origins to this reaction against the past: the decline of journalistic gatekeepers, the horizontality of network connections, the rise of decentralized and 'leaderless' quasi-organizations, the breaking apart of monolithic government bureaucracies, the elective affinities between digital media 
and the new, looser, individualistic identities of progressive postmaterialism and environmental protest, to name but a few.

These disparate themes all seemed tied together for scholars who came of age intellectually with the critiques of politics, society and media that inspired social scientists during the 1990s; those whose outlook was shaped by the collapse of the Berlin Wall and the writings of Foucault, Habermas, Castells and Bourdieu, again, to name but a few. The Internet and digital media looked like the technology of a new era of freedom, in which concentrations of power in the hands of state and corporate elites would be reduced and the authentic voices of marginalized and previously under-represented groups would find untrammelled expression in the public sphere, free from the conformity and aridity of the past.

But we are facing the reality that some of the most consequential attitudes and behaviour enabled by digital media have not been particularly pro-liberal democratic or progressive. Consider, for example, inauthentic social media expression, such as the role of automated bots in social media commentary on the televised debates during the 2016 US presidential election (Kollanyi et al., 2016) and the Brexit referendum (Bastos and Mercea, 2019). Or social media expression designed to cultivate the spread of misinformation, mutual mistrust, intolerance and hatred, such as right-wing commentators' deliberate targeting of news articles about immigration (Anderson and Revers, 2018; Quandt, 2018). There is also a misleading stereotype that progressive digital mobilization has been 'bottom-up' while conservative mobilization has been orchestrated 'from above' (Schradie, 2019: 7).

As a field, we are building the conceptual and methodological tools to come to terms with these developments, but the time is ripe for research to focus attention on the intolerant and democratically dysfunctional aspects of digital media engagement. It is important to start redressing the imbalance created by the previous tendency to focus on optimistic, pro-democratic outcomes.

\section{Research on digital media and politics has tended to employ the engagement gaze}

The second challenge is a progression from the first. It is that research on digital media and politics has tended to employ the engagement gaze. By the 'engagement gaze' I mean that much research on digital media has assumed that more engagement unproblematically creates more democratic goods for the media system and the polity. The key problem is that the engagement gaze has conditioned researchers to look for evidence of engagement and, where 
they find it, to celebrate it as an unalloyed good. This gaze has involved underestimating, or in some cases simply ignoring, the importance of three factors that ought to be considered when appraising any form of engagement: (1) the substantive ideological and political goals of those who become engaged; (2) the extent to which the designed-in incentive structures of any communication environment can make it more likely that some engagement will erode liberal democratic norms of authenticity, rationality and tolerance; and (3) the likelihood that new pathways for engagement will have longer-term, negative systemic consequences for the civic culture of politics.

Boulianne's remarkable meta-analysis of 320 survey-based journal articles on digital media and political participation - more than 20 years of published research - is instructive in this regard (Boulianne, 2018). Very few of those 320 journal articles have much to say about the substantive ideological and political goals of the participation they considered. Ideology appears in only 14 per cent of the 320 studies, and almost always as an explanatory variable, divorced from any specific intentions of participation. Motivations and goals mostly go unmeasured, unhelpfully obscured by the seemingly benign neutrality of the engagement construct itself. Nor did many of those 320 articles focus on how digital media affordances, such as the algorithmic sorting of information in news feeds and other relevant technological design factors, enable and constrain engagement behaviour. Boulianne's analysis covered quantitative survey research. As researchers in the field will recognize, the engagement gaze is equally common in qualitative and case study-based work.

The legacy of underplaying ideological and political goals, of potentially dysfunctional technological design, and long-term consequences, has made it more difficult for scholars of digital media and politics to adapt to the post-2016 climate. And neglecting people's goals for digital engagement, while understandable for avoiding accusations of ideological bias in academia, has opened up opportunities for individuals, groups and movements who seek to produce and circulate ideas that undermine liberal democratic norms. All of this is justifiable when engagement is treated with benign neutrality, as it is under the engagement gaze.

Research on digital media and politics has mostly been driven by the rationality expectation

The third challenge is that much of the research on digital media and politics has been driven by the rationality expectation. By the 'rationality expectation' I mean the assumption that citizens are reflective, act on the best information available in the media system, and that the best resources for that action are to 
be found online because the Internet has comparatively few biases and distortions impacting upon the production and circulation of political knowledge. As Hedrick et al. (2018) have recently argued in a similar vein, much scholarship about digital media and politics has been informed by the assumption of an 'earnest Internet'. This, they suggest, 'generally posits that people act rationally and in good faith; care about facts, truth and authenticity; [and] pursue ends in line with their political and social values and aspirations.'

This assumption has seldom been questioned in research on digital politics, but new research is moving beyond this complacency. It is becoming clear just how widespread trolling and other behaviour that does not fit the rationality expectation is on the so-called 'ambivalent internet' (Phillips, 2016; Phillips and Milner, 2017). The more general problem is how slippery authenticity has become in digitally mediated communication. This goes beyond the long-standing argument that self-reflexivity and 'playfulness' are important parts of online culture. However, playfulness is becoming implicated in a broader culture of generalized indeterminacy. Significant majorities of the public report that, online, it is increasingly difficult to distinguish what is authentic and sincere from what is inauthentic and insincere. This is visible in the post-2016 slump in people's trust in online news and information, as evidenced across many countries in recent survey reports by Pew Research Center (2018) and the Reuters Institute (2018). Only 44 per cent of people in the 37 countries the Reuters Institute surveyed for their 2018 Digital News Report said they trust news overall. But the crisis of trust in news found via search ( 34 per cent) and social media (23 per cent) is far worse. The problem is compounded when one considers that only a minority of the public trusts news that they find through search engines and social media, despite the fact that these surveys also show that search engines and social media are extremely popular gateways for discovering news. So, we are faced with the paradox that most people value encountering news via media they mostly distrust.

Moving beyond the rationality expectation makes it possible to understand these and many other aspects of online politics, from the strategically deployed techniques of 'irony' and 'satire' so often used in the expression of racism, homophobia and sexism on mainstream social media platforms, and the increasingly popular alt-right sites such as 4Chan, 8 Chan and Gab, to the bizarre, insider memes of the \#GamerGate movement opposed to women's influence in the video game industry (and public life more generally), and the emergence of artificial intelligence (AI)-produced 'deep fake' disinformation videos. If the last of these becomes a regular feature of political events, as is already the case with fake accounts and social media bots, one possible outcome is that citizen scepticism turns to cynicism and apathy: the withdrawal that accompanies the 
attitude that so little political information online can be trusted because establishing the truth is so exhausting. Fears about disinformation often hinge on whether people will be deceived by falsehoods, but the lesson of the past is that people are just as likely to become uncertain about the truth and to withdraw into the private sphere. This was an important strand of the critique of the neo-Stalinist states in Eastern Europe (e.g., Havel, 1985).

We are already seeing early signs of this culture of indeterminacy. For example, Toff and Nielsen's qualitative research in the north of England has shown that 'I don't know what to believe' has become an important response to the uncertainties of encountering news on social media and private messaging apps (Toff and Nielsen, 2018). Meanwhile, Petersen et al. (2018) have gathered survey data that show what they term a 'need for chaos' is an important motivation among those in Western democracies who share false rumours and conspiracy theories. As the authors put it, '[T]he sharing of hostile political rumors is not motivated by a desire to aid actors within the system. Instead, it is motivated by a desire to tear down the system.' Such motivations are present among about 40 per cent of the US population (Petersen et al., 2018). All of this points to an unsettling vision of the future, but to see it and address it requires relaxing the rationality expectation and coming to grips with some of the wilder frontiers of online mis- and disinformation.

Research on digital media and politics has often underestimated the trade-offs between affective solidarity and rational deliberation

The final challenge is that previous research on digital media and politics has tended to underestimate the inevitable trade-offs between affective solidarity and rational deliberation. A new wave of research is foregrounding emotion as a key force in media, politics and journalism (e.g., Papacharissi, 2015; Wahl-Jorgensen, 2018). But there is a tension in this work. As Papacharissi has convincingly demonstrated, affect interacts with the affordances of social media, particularly circulation, repetition and recursion, and plays a role in opinion formation and collective action by contributing to the social solidarity and identity that are essential precursors to political mobilization (Papacharissi, 2015). But the social force of affect online is also such that the identities from which it springs, and which it shapes and reinforces, seem to be highly resistant to challenge and subversion. Identity based on affective ties seems to be particularly difficult to dislodge online. This point underlies much of the anxiety about 'filter bubbles' and 'echo chambers', it informs much of the empirical research on misinformation and misperceptions, and as Kreiss argues, it ultimately implies the fracturing of civic epistemology, 'the 
basis upon which people understand and agree upon political facts and truths' (Kreiss, 2017; see also Waisbord, 2018).

Arlie Russell Hochschild's recent book Strangers in their Own Land (Hochschild, 2016), about conservative identity in the American South, is instructive in this regard. While Hochschild has little to say about the role of media, she reveals much about how complex, multilayered emotional substructures condition daily life and attitudes to political and economic authority. This provides a useful perspective for exploring the roots of intolerance and misinformation online.

Animating affective divides is what Hochschild terms 'deep stories'. A deep story is essentially an overarching, metaphorical sensibility. It serves as an emotionally charged basis for everyday orientations towards social, cultural, economic and political reality. The deep story feeds identity, social division and resentment toward the other side, however that side is defined. As Hochschild puts it:

A deep story is a feels-as-if story - it's the story feelings tell, in the language of symbols. It removes judgment. It removes fact. It tells us how things feel . . . And I don't believe we understand anyone's politics, right or left, without it. For we all have a deep story.

Concerns about online echo chambers may be exaggerated, not least because the empirical evidence for these phenomena has always been mixed. But the ways in which social media platforms have positioned behavioural metrics cues and algorithmic sorting of content at the centre of their business models for garnering attention has had effects on group attitudes and behaviour. The US misinformation and bot crises provide evidence of how Facebook's news feed and Twitter's hashtags have introduced surprising new vulnerabilities, but the problem is a larger one: content that reinforces one's identity is more accessible than ever to those in society who are motivated to have their identity reinforced, even if that identity is based on democratically dysfunctional norms, such as the refusal - fuelled by misogyny, xenophobia or racism - to hear the other side. Decades of political psychology research on selective exposure have demonstrated that many people are predisposed to having their existing attitudes reinforced by their media consumption habits, but we are only in the early stages of learning about how selective exposure informs people's online production and sharing habits.

This is an example of when an understandable cognitive bias - the need to have one's views reinforced to reduce risk and uncertainty - converges with 
social media affordances: visible metrics cues and algorithmic curation of feeds and hashtags. This heady mix is highly conducive to building collective action through affective solidarity; and quickly, even if the information is false. But it is not so beneficial for rational deliberation and building consensus through recognition and respect for difference. The inevitable trade-offs for liberal democratic political culture caused by this tension ought to be examined more carefully in future research.

Technological affordances have played only a minor role in traditional public opinion scholarship, which has been mostly about the message, not the medium. And yet, public opinion research has paid attention to problematic aspects of how public opinion is formed, for example through the study of elite cues (e.g., Edelman, 1988; Zaller, 1992). It has also considered the limits to genuinely informed public opinion when media exposure is conditioned by partisanship, polarization and motivated reasoning. Attention to how the affordances of digital media interact with the constraints that we know shape citizens' reasoning about public affairs can update these approaches. And, of course, we should also bear in mind that social media affordances are not always what they appear to be on the surface. They are vulnerable to being exploited, often in hidden ways, by actors of various kinds who seek to distort the economy of attention and influence public opinion through subterfuge, spreading false rumours, or splicing together information from a range of different sources, some reputable, some not.

As social media increased in popularity over the last decade, attention to elite cues was mostly sidelined in favour of conceptual frameworks that focused on what seemed to be so 'new' about 'new media': individual agency, the erosion of traditional gatekeepers, and user-generated content (e.g., Bruns, 2008). But we are learning that techniques of elite persuasion, while they have been reconfigured, are still highly important for the formation of public opinion and political behaviour. An important task, then, is to identify the conditions under which democratically dysfunctional information spreads online, exposing potentially large numbers to content which - and this is crucial - many then choose to share in their own social media networks.

\section{Conclusion}

In this chapter I have argued that research on digital politics ought to be recalibrated to explain how digital media can shape public opinion in ways that are dysfunctional for liberal democratic societies. As I remarked at the beginning, 
there are no easy solutions, but it is also the case that this task is already under way across the social sciences. The overarching challenge we face is that disinformation, misinformation, hatred and intolerance are radically networked like never before, and the raw materials for individuals and organizations to behave in democratically dysfunctional ways are diverse and multiple.

In the context of this new crisis of public communication, a key task ahead is explaining how social, psychological and technological variables converge in ways that shape how individuals form identities and opinions about the political world. Can we bring these objects of analysis together - social and psychological variables, and the affordances of digital media - to help understand how liberal democracy is evolving as the great expansion of digital media platforms nears completion? Can we develop better understandings of how social media interact with, and potentially reconfigure, the different constraints on rational opinion formation at the individual level? Is it possible to identify the blend of cognitive biases, social identities and affordances that align to produce democratically dysfunctional behaviour that threatens the future of liberal democracy? And, finally - perhaps the biggest challenge of all - can we, as scholars, effectively intervene in public and policy debates to minimize the impact of these forces in the interests of promoting liberal democratic norms?

\section{Acknowledgements}

I thank Samantha Bradshaw, Nick Couldry, David Karpf, Sarah Anne Ganter, Philip N. Howard, Daniel Kreiss, Shannon C. McGregor, Lisa-Maria Neudert, Rasmus Kleis Nielsen, Stuart Soroka, Talia Stroud, Peter Van Aelst and Gadi Wolfsfeld for their comments on an earlier presentation of these ideas. Any errors or shortcomings in this chapter are mine.

\section{Note}

1. I am grateful to Dr Shelley Boulianne for sending me the full variable list for her 2018 article. 


\section{References}

Anderson, C.W. and Revers, M. (2018) 'From Counter-Power to Counter-Pepe: The Vagaries of Participatory Epistemology in a Digital Age', Communication and Media, 6(4), pp. 24-35.

Bastos, M. and Mercea, D. (2019) 'The Brexit Botnet and User-Generated Hyperpartisan News', Social Science Computer Review, 37(1), pp. 38-54.

Boulianne, S. (2018) 'Twenty Years of Digital Media Effects on Civic and Political Participation', Communication Research. doi: 10.1177/0093650218808186.

Bruns, A. (2008) Blogs, Wikipedia, Second Life, and Beyond: From Production to Produsage. New York: Peter Lang.

Edelman, M. (1988) Constructing the Political Spectacle. Chicago, IL: University of Chicago Press.

Havel, V. (1985) The Power of the Powerless: Citizens Against the State in Central Eastern Europe. London: Routledge.

Hedrick, A., Karpf, D. and Kreiss, D. (2018) Book Review: 'The Earnest Internet vs. the Ambivalent Internet', International Journal of Communication, 12(8), pp. 1057-64.

Hochschild, A.R. (2016) Strangers in their Own Land: Anger and Mourning on the American Right. New York: New Press.

Kollanyi, B., Howard, P.N. and Woolley, S.C. (2016) 'Bots and Automation over Twitter During the First US Presidential Debate (Comprop Data Memo 2016.1)'. Computational Propaganda Project, Oxford Internet Institute. Available at http:// blogs.oii.ox.ac.uk/politicalbots/wp-content/uploads/sites/89/2016/10/Data-Memo -First-Presidential-Debate.pdf/.

Kreiss, D. (2017) 'The Fragmenting of the Civil Sphere: How Partisan Identity Shapes the Moral Evaluation of Candidates and Epistemology', American Journal of Cultural Sociology, 5(3), pp. 443-59.

Papacharissi, Z. (2015) Affective Publics: Sentiment, Technology, and Politics. New York: Oxford University Press.

Petersen, M.B., Osmundsen, M. and Arceneaux, K. (2018) 'A "Need for Chaos" and the Sharing of Hostile Political Rumours in Advanced Democracies'. Paper presented to the American Political Science Association Annual Meeting, 2018. Available at https://psyarxiv.com/6m4ts.

Pew Research Center (2018) News Use Across Social Media Platforms 2018. Washington, DC: Pew Research Center.

Phillips, W. (2016) This Is Why We Can't Have Nice Things: Mapping the Relationship Between Online Trolling and Mainstream Culture. Cambridge, MA: MIT Press.

Phillips, W. and Milner, R.M. (2017) The Ambivalent Internet: Mischief, Oddity, and Antagonism Online. Cambridge: Polity Press.

Quandt, T. (2018) 'Dark Participation', Media and Communication, 6(4), pp. 36-48.

Reuters Institute for the Study of Journalism (2018) Reuters Institute Digital News Report 2018. Oxford: Reuters Institute. http://media.digitalnewsreport.org/wp -content/uploads/2018/06/digital-news-report-2018.pdf.

Schradie, J. (2019) The Revolution That Wasn't: How Digital Activism Favors Conservatives. Cambridge, MA: Harvard University Press.

Shirky, C. (2008) Here Comes Everybody: The Power of Organizing Without Organizations. London: Allen Lane.

Toff, B. and Nielsen, R.K. (2018) "“I Just Google It": Folk Theories of Distributed Discovery', Journal of Communication, 68(3), pp. 636-57. 
Wahl-Jorgensen, K. (2018) Emotions, Media and Politics. Cambridge: Polity.

Waisbord, S. (2018) 'Truth is What Happens to News: On Journalism, Fake News, and Post-Truth', Journalism Studies, 19(13), pp. 1866-78.

Zaller, J. (1992) The Nature and Origins of Mass Opinion. New York: Cambridge University Press. 